\title{
Frequent epidermal growth factor receptor gene mutations in malignant pleural effusion of lung adenocarcinoma
}

\author{
S-G. Wu*, C-H. Gow*, C-J. Yu*, Y-L. Changף, C-H. Yang+, Y-C. Hsu*, J-Y. Shih*, \\ Y-C. Lee ${ }^{\S}$ and P-C. Yang*
}

ABSTRACT: Malignant pleural effusions (MPEs) are often observed in lung cancer, especially adenocarcinoma. Epidermal growth factor receptor (EGFR) gene mutations are usually detected in lung adenocarcinoma. The purpose of the present study was to investigate the EGFR mutation rate in MPEs of lung adenocarcinoma.

Between June 2005 and December 2006, 136 MPEs from lung adenocarcinoma were collected for EGFR mutation detection. In addition, between April 2001 and November 2004, 91 surgically resected specimens of lung adenocarcinoma from patients without MPEs were assessed for EGFR mutation.

The EGFR mutation rate was significantly higher in the patients with MPEs than in the patients without (68.4\% versus $50.5 \%$ ). The EGFR mutation rate in patients with MPEs was not associated with sex, smoking history, age or cancer stage. By multivariate analysis, an age of $<65$ yrs, never smoking, Eastern Cooperative Oncology Group performance status 0-1, and EGFR mutation were significantly associated with a longer overall survival for lung adenocarcinoma patients with MPEs.

The patients with malignant pleural effusions related to lung adenocarcinoma had a higher epidermal growth factor receptor gene mutation rate than the patients from whom surgically resected specimens were taken. Epidermal growth factor receptor tyrosine kinase inhibitors may be the treatment of choice for lung adenocarcinoma with malignant pleural effusions in east Asia.

KEYWORDS: Epidermal growth factor receptor, lung cancer, mutation, pleural effusion

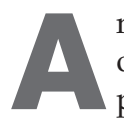

nnually, there are $\sim 1.2$ million new cases of lung cancer globally, with $\sim 1.1$ million patients dying due to the disease [1]. Platinum-based chemotherapy has a partial response in only $30 \%$ of patients with advanced nonsmall cell lung cancer (NSCLC) [2].

Epidermal growth factor receptor (EGFR) tyrosine kinase inhibitors (TKIs) are used in the treatment of NSCLC. EGFR TKIs have a higher response in specific subgroups, including: females; never smokers; adenocarcinoma histology; and east Asians [3-5]. These subgroups also have higher EGFR mutation rates [6]. A better response to EGFR TKIs and prolonged survival are related to EGFR mutations, including inframe deletions and point mutations [7-9].

Malignant pleural effusions (MPEs) are often observed in lung cancer, especially adenocarcinoma, because it is a tumour that grows in the periphery of the lung and easily invades the pleural cavity [10]. MPEs also indicate an advanced stage of disease or disease progression.
In total, $\sim 15 \%$ of patients have pleural effusion at the initial diagnosis of lung cancer [10]. Thoracentesis is necessary for diagnosis and treatment. MPEs can develop as a direct consequence of cancer cell dissemination into the pleural space; however, the exact mechanisms are not fully understood [11]. MPEs may result from the combination of both decreased capacity of the lymphatics to remove fluid and increased pleural fluid formation [11]. The latter mechanism may be related to an increase in the vascular permeability, and vascular endothelial growth factor (VEGF) plays an important role in increasing the permeability of the vasculature [12]. Median VEGF levels in pleural fluid are higher in MPEs than nonmalignant pleural effusions [13]. In addition to VEGF, other molecular factors or tumour markers can also be detected in MPEs. HsIEH et al. [14] demonstrated that pigment epithelium-derived factor and fibrinogen precursors are expressed at lower levels in MPEs than in transudates. DAI et al. [15] showed that p53 and Kras gene mutation patterns are effective markers
AFFILIATIONS

*Depts of Internal Medicine,

"Pathology,

${ }^{+}$Oncology,

${ }^{\S}$ Surgery, National Taiwan University Hospital, Taipei, and

\#Division of Critical Care Medicine, Dept of Emergency and Critical Care Medicine, Lotung Poh-Ai Hospital, Yi-Lan, Taiwan.

CORRESPONDENCE

J-Y. Shih

Dept of Internal Medicine

National Taiwan University Hospital

No. 7

Chung-Shan South Road

Taipei 100

Taiwan

Fax: 886223582867

E-mail: jyshih@ntu.edu.tw

Received:

December 112007

Accepted after revision:

May 132008

SUPPORT STATEMENT

The authors thank the National

Science Council, Taiwan for

their support with the grant NSC

95-2314-B-002-113-MY3 (for

J-Y. Shih).

STATEMENT OF INTEREST

None declared.

European Respiratory Journa

Print ISSN 0903-1936

Online ISSN 1399-3003 
for the detection of recurrent lung carcinoma in cytological specimens of pleural effusions.

MPE is collected via very easy techniques, in contrast to other invasive techniques, such as biopsy and surgery, which are necessary to obtain tissue of other metastatic sites. Mutations of EGFR can also be detected in pleural effusion samples [16]. EGFR mutation screening in pleural effusion is useful for the prediction of the clinical outcome of lung cancer patients treated with gefitinib $[16,17]$. In order to understand how frequently EGFR mutations occur in MPEs of lung adenocarcinoma, the present authors examined the sequences of exons 18-21 of EGFRs in MPEs of lung adenocarcinoma. The mutation rate of MPEs and the mutation rate of surgically resected specimens were then compared. In addition, clinical information was collected to analyse the prognostic factors of overall survival in the patients with lung adenocarcinoma with MPEs.

\section{MATERIALS AND METHODS}

\section{Patients and tissue procurement}

Between June 2005 and December 2006, 383 consecutive samples of pleural effusion were collected from 273 patients who had received thoracentesis in the chest ultrasonography examination room of the National Taiwan University Hospital (Taipei, Taiwan). This study was approved by the institutional review board of the National Taiwan University Hospital, and all patients had signed an informed consent form before the thoracentesis was performed. The primary malignant tumours or MPEs were confirmed by pathology or cytology reports. Of the 273 patients, 164 had lung adenocarcinoma and the other 109 patients had malignancy other than lung adenocarcinoma or nonmalignancy-related pleural effusions. Among the 164 patients with lung adenocarcinoma, the cytology of pleural effusions was negative in 28 patients. Therefore, 136 MPEs of lung adenocarcinoma were assessed for EGFR mutations. These 136 MPEs were obtained before treatment with gefitinib, or erlotinib if the patients received EGFR TKI therapy. For comparison, 91 surgically resected specimens of lung adenocarcinoma archived from April 2001 to November 2004 were also retrived. Informed consent about the use of these specimens for future molecular studies with approval of the institutional review board was obtained before surgery. The retrospective use of archival tissue for EGFR gene analysis was approved by the institutional review board of the National Taiwan University Hospital. The clinical information of all the patients was recorded, including age, sex, smoking history, lung cancer stage, performance status (Eastern Cooperative Oncology Group performance status (ECOG PS)), treatment regimens and maximal response. Patients who had smoked $<100$ cigarettes in their lifetime were categorised as never smokers. Those who smoked cigarettes within $1 \mathrm{yr}$ of the diagnosis were categorised as current smokers. The others were categorised as former smokers.

\section{Collection of pleural effusion fluid and surgically resected specimens}

The pleural effusion fluid was collected into heparinised tubes. A 1 -mL sample of the fluid was centrifuged at $250 \times g$ for $10 \mathrm{~min}$ at room temperature, and the cell pellet frozen. Specimens of lung adenocarcinoma tissue obtained at surgery were immediately snap-frozen in liquid nitrogen and stored for later use. Total RNA was isolated using Tri-reagent (Molecular Research Center, Inc., Cincinnati, $\mathrm{OH}$, USA) and stored at $-80^{\circ} \mathrm{C}$ until RNA extraction was performed. RNA was extracted from cell lysates with a Qiamp RNA Mini Kit (Qiagen, Hilden, Germany) according to the protocol in the manufacturer's instructions. The RNA obtained was eluted in $50 \mu \mathrm{L}$ of sterile bi-distilled buffer. The amounts of RNA extracted were measured with spectrophotometry.

\section{PCR amplification and direct sequencing}

The four exons (exons 18-21) that code for the tyrosine kinase domain of the EGFR gene were amplified with a forward primer (5'-AGCTTGTGGAGCCTCTTACACC-3') and reverse primer (5'-TAAAATTGATTCCAATGCCATCC-3'), as reported in a prior study [8]. The RT-PCR was performed previously as reported [8], using a Qiagen OneStep RT-PCR Kit (Qiagen). The RT-PCR conditions were as previously described [8]. RT-PCR amplicons were purified and sequenced using the Big Dye Terminator sequencing kit (Applied Biosystems, Foster City, CA, USA) according to the manufacturer's instructions. Sequencing products underwent electrophoresis on an ABI PRISM 3100 (Applied Biosystems). Both the forward and reverse sequences obtained were analysed by basic local alignment search tool against the cDNA sequence of the EGFR gene (accession number NM005228) and chromatograms were examined manually. PCR amplicons were sequenced in both sense and antisense directions. EGFR mutations detected in the initial round of sequencing were confirmed by subsequent rounds of independent RT-PCR and sequencing reactions. Only specimens in which a mutation was identified in both rounds were recorded as mutation positive. Mutations were also checked against the single nucleotide polymorphism database.

\section{Antitumour therapy and response evaluation of the patients with MPEs of lung adenocarcinoma}

The antitumour response of the patients was evaluated by chest radiography every 2-4 weeks and by computed tomography of the disease sites every 8-12 weeks after treatment; this is routine practice in the present authors' institution. For the measurable solid tumours, the unidimension method was used according to the Response Evaluation Criteria in Solid tumours (RECIST) guidelines [18]. Partial response and stable disease were confirmed by a sustained 4-week follow-up. Overall survival after antitumour therapy was calculated from the date of initiation of treatment to the date of death, last follow-up or the final follow-up day of the study, which was September 1, 2007.

Toxicity of EGFR TKIs was also recorded, and was graded according to the National Cancer Institute Common Toxicity Criteria Version 3.0.

\section{Statistical analysis}

All categorical variables were analysed with Pearson's Chisquared test, except where a small size required the use of Fisher's exact test. Overall survival was compared by the logrank test, and multivariate analysis for overall survival was performed using the Cox linear regression method. Two-sided p-values $<0.05$ were considered significant. 


\section{RESULTS}

\section{Clinical characteristics and EGFR mutations of the surgically resected lung adenocarcinoma patients}

In total, 91 surgically resected specimens were assessed for the EGFR mutation (table 1). The median (range) age of the 91 patients was 63.4 (37.5-85.4) yrs. Three stage-IIIB patients had satellite tumour nodules within the same lobe as the primary tumour, and they received lobectomies. Two stage-IV patients, who both had two lung lesions over the right middle lobe and right lower lobe without other distant metastasis lesions, received bi-lobectomies.

In total, 46 out of 91 surgically resected lung adenocarcinoma had EGFR mutations. The EGFR mutation rate was 50.5\%. The EGFR mutations included 19 L858R, 23 deletions in exon 19 and four other types (767-769 duplication ASV, P771_ H773ins YNP+H773Y, K860I+L861Q and L861Q). EGFR mutation rates of the surgically resected lung adenocarcinoma were not significantly different by sex (49\% of males versus $52.5 \%$ of females; $p=0.742)$, age $(p=0.746)$ or smoking status $(54.7 \%$ of never smokers versus $44.7 \%$ of former or current smokers; $\mathrm{p}=0.348$; table 1).

Of the 91 patients, 14 took EGFR TKIs after tumour recurrence. Of these, seven patients had EGFR mutations, and the other seven patients were wild type. Five patients with a positive EGFR mutation and three patients of wild type responded to EGFR TKI treatment. However, the patient numbers were too small for further analysis.

\section{Clinical characteristics and EGFR mutations of the lung adenocarcinoma patients with MPE}

MPEs were assessed for EGFR mutations in 136 patients (table 2). The median (range) age of the 136 patients was 66.1 (28.7-90.6) yrs. Two (1.5\%) patients did not complete staging work-up of lung cancer and they were lost to follow-up.

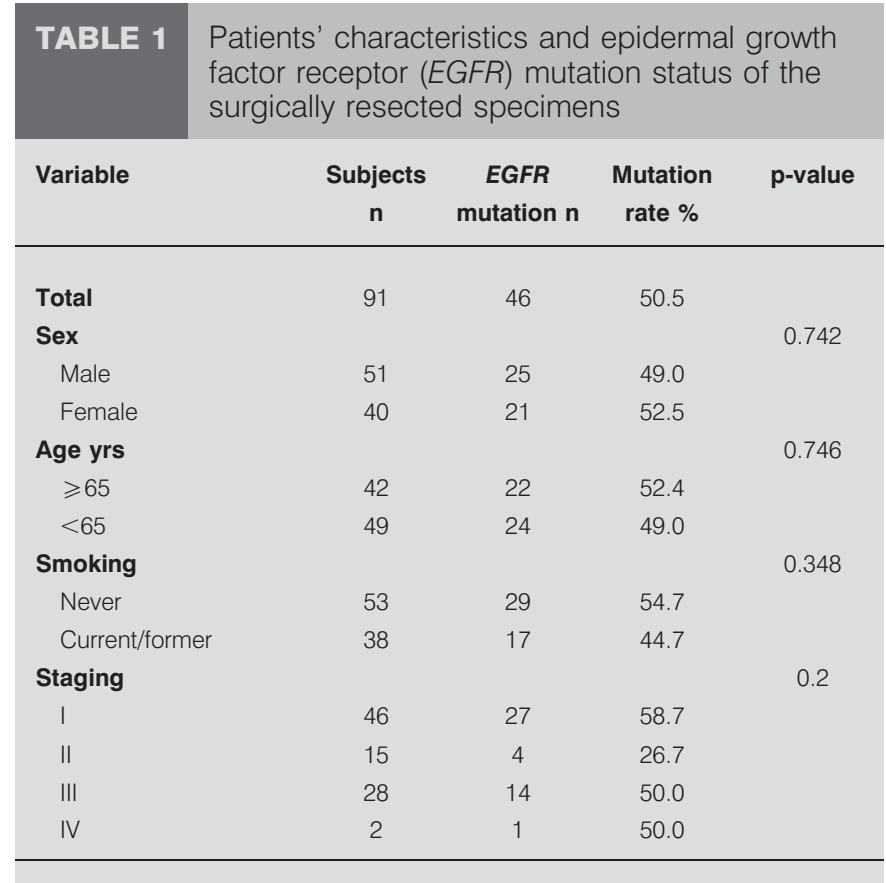

In total, 93 out of 136 patients with MPEs of lung adenocarcinoma had positive EGFR mutations. The mutation rate was $68.4 \%$. The EGFR mutations included 50 L858R, 32 deletions in exon 19 , and 11 other types. The 11 other types included three G719A, one G719A+S720F, one G719A+S768I, one E746V+ L747P, one L747P, one 767-769 duplication ASV, one 768-770 duplication SVD, one L861Q and one R776H+L861Q. EGFR mutation rates of the adenocarcinoma patients with MPEs were not significantly different by sex $(64.2 \%$ of males versus $71.1 \%$ of females; $\mathrm{p}=0.396)$, age $(\mathrm{p}=0.734)$ or smoking status (70.5\% of never smokers versus $63.4 \%$ of former or current smokers; $\mathrm{p}=0.413$; table 2).

Of the 136 patients with MPEs, 111 patients initially had pleural effusions at the diagnosis of lung adenocarcinoma. Of the 111 patients, $77(68.5 \%)$ had EGFR mutations. The mutation rate of initial pleural effusions related to lung adenocarcinoma was similar to the total 136 MPEs (68.5\% versus $68.4 \%$ ).

The patients with MPEs of lung adenocarcinoma had a higher EGFR mutation rate than the patients with surgically resected lung adenocarcinoma (68.4\% versus 50.5\%; $\mathrm{p}=0.007$; table 3 ). Interestingly, the mutation rates of deletion in exon 19 in MPEs and surgically resected specimens were not significantly different (23.5\% versus $25.3 \%$ ). However, the patients with MPEs of lung adenocarcinoma had a higher L858R mutation rate than the patients with surgically resected lung adenocarcinoma $(36.8 \%$ versus $20.9 \%$; $\mathrm{p}=0.011$; table 3$)$.

\section{Response of adenocarcinoma with MPEs treated with EGFR TKI}

Of the 136 patients with MPEs of lung adenocarcinoma, 71 had received EGFR TKI treatment (gefitinib $250 \mathrm{mg} \cdot$ day $^{-1}$ or erlotinib $150 \mathrm{mg} \cdot \mathrm{day}^{-1}$ ). Two patients were lost to follow-up before treatment and the other 63 patients received other antitumour therapy. Of the 71 patients treated with EGFR TKI, 38 had partial response. Those included one wild type, 23 L858R, 11 deletions in exon 19, one G719A, one L861Q and one

\begin{tabular}{|c|c|c|c|c|}
\hline \multirow{2}{*}{$\begin{array}{l}\text { TABLE } 2 \\
\text { Variable }\end{array}$} & \multicolumn{4}{|c|}{$\begin{array}{l}\text { Patient characteristics and epidermal growth } \\
\text { factor receptor (EGFR) mutation status of } \\
\text { malignant pleural effusions }\end{array}$} \\
\hline & $\begin{array}{c}\text { Subjects } \\
n\end{array}$ & $\begin{array}{c}\text { EGFR } \\
\text { mutation } \mathrm{n}\end{array}$ & $\begin{array}{c}\text { Mutation } \\
\text { rate } \%\end{array}$ & p-value \\
\hline Total & 136 & 93 & 68.4 & \\
\hline Sex & & & & 0.396 \\
\hline Male & 53 & 34 & 64.2 & \\
\hline Female & 83 & 59 & 71.1 & \\
\hline Age yrs & & & & 0.734 \\
\hline$\geqslant 65$ & 73 & 49 & 67.1 & \\
\hline$<65$ & 63 & 44 & 69.8 & \\
\hline Smoking & & & & 0.413 \\
\hline Never & 95 & 67 & 70.5 & \\
\hline Current/former & 41 & 26 & 63.4 & \\
\hline Staging & & & & 0.944 \\
\hline IIIB & 26 & 18 & 69.2 & \\
\hline IV & 108 & 74 & 68.5 & \\
\hline Unknown & 2 & 1 & 50.0 & \\
\hline
\end{tabular}


TABLE 3 The difference in epidermal growth factor receptor (EGFR) mutations between adenocarcinoma patients with malignant pleural effusions and surgically resected specimens from other adenocarcinoma patients

\begin{tabular}{lcccc} 
& Wild type & L858R & Deletion in exon 19 & Others \\
\hline Malignant pleural effusion & $43(31.6)$ & $50(36.8)$ & $32(23.5)$ & $11(8.1)$ \\
Surgically resected specimen & $45(49.5)$ & $19(20.9)$ & $23(25.3)$ & $4(4.4)$ \\
\hline
\end{tabular}

Data are presented as $n$ or $n(\%) . p=0.017$ for MPE versus surgically resected specimens for positive and negative of EGFR mutations; $p=0.011$ for MPE versus surgically resected specimens with L858R mutations.

combined EGFR mutation (G719A+S720F; table 4). For the overall survival analysis of the 136 patients with lung adenocarcinoma and MPEs, the median overall survival was longer for patients with EGFR mutations than for patients with wild-type EGFR (median 21.4 months, 95\% confidence interval (CI), 17.9-24.9 months versus 11.5 months, 95\% CI 7.4-15.6 months; $\mathrm{p}=0.005$ by log-rank test). Multivariate analysis was performed by the Cox regression model for the potential prognostic factors, including: age, smoking status, ECOG PS, EGFR mutation (table 5). Lung adenocarcinoma patients with MPEs who were aged $<65$ yrs $(p=0.011)$, who never smoked $(p=0.027)$, with ECOG PS $0-1 \quad(p<0.001)$ and EGFR mutation $(p=0.001)$ were found to be associated with a longer overall survival.

The toxicity of EGFR TKIs were distributed from grade 1 to grade 3 , and no patients had grade 4 toxicity. The most common toxicity included diarrhoea $(24 \%)$, skin rash $(38 \%)$, acne $(31 \%)$, dry skin $(22 \%)$, pruritus $(22 \%)$ and anorexia $(20 \%)$. Grade 3 events included one diarrhea (1\%), one skin rash $(1 \%)$ and one acne (1\%). Neither grade 4 toxicity nor interstitial pneumonitis was recorded.

\section{DISCUSSION}

In the present study, patients with lung adenocarcinoma with MPEs had a higher EGFR mutation rate than patients with surgically resected adenocarcinoma. The EGFR mutation rate in MPEs of lung adenocarcinoma was $\sim 70 \%$, regardless of the patients' sex, smoking status or age.

MPEs are a common clinical problem for patients with lung adenocarcinoma. Thoracentesis may not only relieve dyspnoea [19], but is also an easy way to collect malignant cells from pleural effusion for molecular studies, in contrast to other invasive techniques used to biopsy the primary tumour or its metastases in clinical practice. EGFR mutations could be detected in MPEs, and are useful for the prediction of response to gefitinib, as shown in the present study and others [16, 17].

The present study revealed a $68.4 \%$ EGFR mutation rate in lung adenocarcinoma with MPEs, which is higher than in prior published research. SOH et al. [16] reported an EGFR mutation rate of $24.5 \%$ (13 out of 53) in MPEs related to lung adenocarcinoma. However, only deletions in exon 19 and

TABLE 4 Epidermal growth factor receptor (EGFR) mutation status and response of EGFR tyrosine kinase inhibitor in patients of malignant pleural effusions

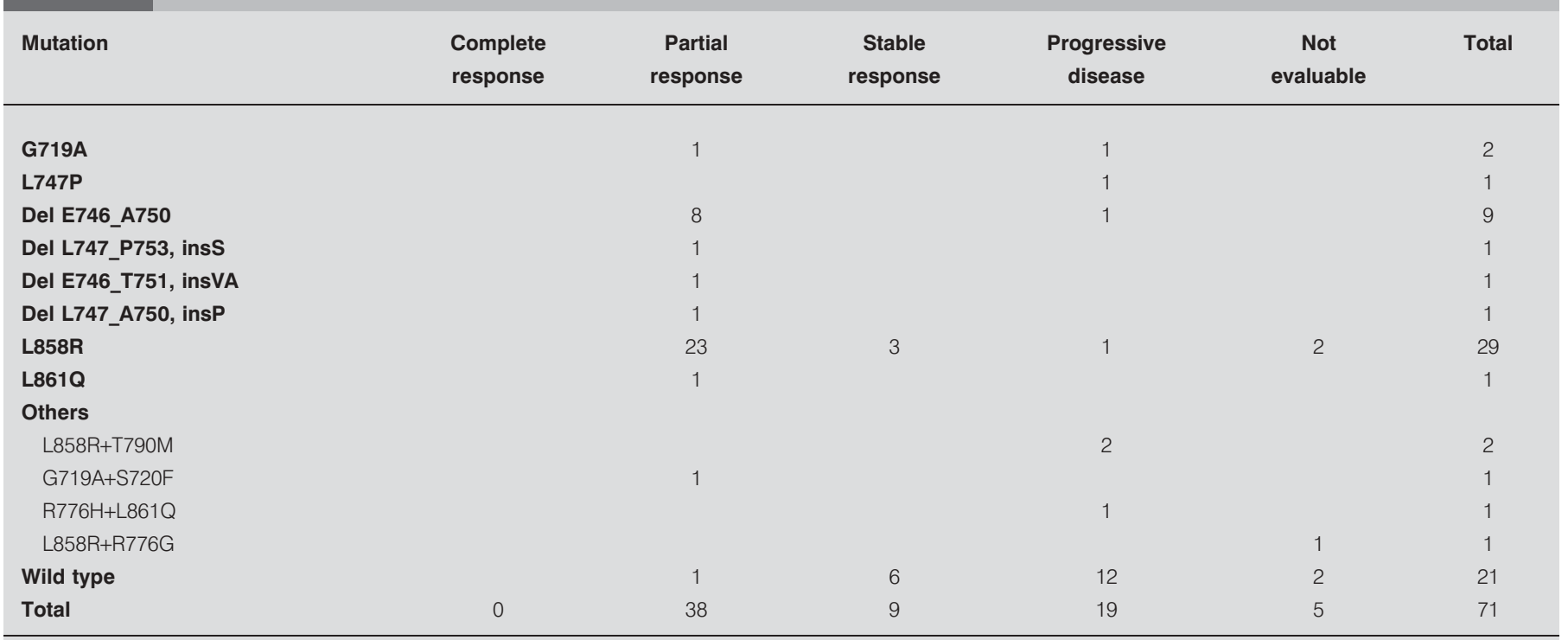

Del: deletion; ins: insertion 


\begin{tabular}{|c|c|c|c|c|}
\hline TABLE 5 & $\begin{array}{l}\text { ultivariate } \\
\text { erall sur } \\
\text { atients wit }\end{array}$ & $\begin{array}{l}\text { analysis of pro } \\
\text { val of the } 136 \\
\text { h malignant ple }\end{array}$ & $\begin{array}{l}\text { gnostic fac } \\
\text { idenocarci } \\
\text { ural effusic }\end{array}$ & $\begin{array}{l}\text { tors for } \\
\text { noma } \\
\text { ns }\end{array}$ \\
\hline \multirow[t]{2}{*}{ Factors } & \multirow{2}{*}{$\begin{array}{c}\text { Patients } \\
\text { n }\end{array}$} & \multirow{2}{*}{$\begin{array}{l}\text { Median survival } \\
\text { months }\end{array}$} & \multicolumn{2}{|c|}{ p-value } \\
\hline & & & $\begin{array}{c}\text { Univariate } \\
\text { analysis }\end{array}$ & $\begin{array}{c}\text { Multivariate } \\
\text { analysis }\end{array}$ \\
\hline Sex & & & 0.679 & \\
\hline Female & 83 & 19.2 & & \\
\hline Male & 53 & 17.0 & & \\
\hline Age yrs & & & 0.002 & 0.011 \\
\hline$<65$ & 63 & 23.1 & & \\
\hline$\geqslant 65$ & 73 & 12.9 & & \\
\hline Smoking & & & 0.025 & 0.027 \\
\hline Never & 95 & 19.8 & & \\
\hline Current/former & 41 & 13.0 & & \\
\hline ECOG PS & & & $<0.001$ & $<0.001$ \\
\hline $0-1$ & 96 & 21.4 & & \\
\hline $2-4$ & 40 & 6.5 & & \\
\hline Stage & & & 0.635 & \\
\hline III & 26 & 19.6 & & \\
\hline IV & 108 & 19.2 & & \\
\hline EGFR & & & 0.005 & 0.001 \\
\hline Mutation & 93 & 21.4 & & \\
\hline Wild type & 43 & 11.5 & & \\
\hline EGFR TKI & & & 0.189 & \\
\hline No & 65 & 19.6 & & \\
\hline Yes & 71 & 19.8 & & \\
\hline
\end{tabular}

ECOG PS: Eastern Cooperative Oncology Group performance status; EGFR: epidermal growth factor receptor; TKI: tyrosine kinase inhibitor

L858R were analysed [16]. KIMURA et al. [20] demonstrated a $28.2 \%$ (11 out of 39 ) EGFR mutation rate and considered that the lower frequency of EGFR mutation was related to enrolling patients with false-negative results. KIMURA et al. [21] showed a $13 \%$ (3 out of 23) EGFR mutation rate by direct sequence of EGFR mutations in MPEs related to lung adenocarcinoma in another study, with $9.1 \%$ (1 out of 11 ) in females and $10 \%(1$ out of 10) in never smokers. It should be noted that more current or former smoking patients were enrolled into the KIMURA et al. [21] study. The EGFR mutation rate of MPEs ranged $9.1-68.4 \%$. This variability probably reflects methodology, selection of patients, and geographic differences. Besides, the pleural effusion samples obtained in the present study were all positive for malignant cells by cytological examination, and this increases the detection rate of EGFR mutations.

Breast and colon cancers have been established as the models for a multistep oncogenesis process during which the accumulation of genetic mutations results in the development of an invasive phenotype $[22,23]$. The EGFR mutation might be involved in the pathogenesis of lung adenocarcinoma. EGFR mutations were more frequent in patients with advanced stage disease (MPE) when compared with more early stages (surgically resectable). The difference of the EGFR mutation rate between the MPEs and the surgically resected lung adenocarcinoma might reflect the process of carcinogenesis. TANG et al. [24] found identical EGFR mutations detected in the normal respiratory epithelium in $43 \%$ of patients with EGFR mutant adenocarcinomas. TOMIZAWA et al. [25] also demonstrated that EGFR mutations were more frequently observed in the advanced stage of NSCLC. MATSUMOTO et al. [26] reported frequent EGFR mutations in brain metastasis of lung adenocarcinoma in a case series of 19 patients. MAтSUмото et al. [26] study showed a $63 \%$ EGFR mutation rate, which is similar to the present study in MPEs. The higher incidence of EGFR mutations in MPEs and brain metastasis than in surgically resected lung tumours implies that EGFR mutation is more frequent in patients with advanced stages when compared with earlier stages. Further studies are necessary to address this issue.

The incidence of EGFR mutations in NSCLC ranges from $10 \%$ to $>50 \%[17,27-31]$. EGFR mutations of NSCLC are more frequent in females, nonsmokers and in Asian countries [6, 25]. Geographic (ethnic) differences and methodology in detection of EGFR mutations may result in variability. The EGFR mutation rate in surgically resected adenocarcinoma was $36 \%$ in Korea, $42-55.6 \%$ in Japan and 55\% in Taiwan [27, 31, 32]. Reports from Korea and Japan show that the EGFR mutation rates of lung adenocarcinomas are higher in females (females versus males: $53.1-76.3 \%$ versus $22-36 \%$ ) and never smokers (never smokers versus smokers: $57.4-83 \%$ versus $21-32 \%$ ) [27-30, 32, 33]. However, HuANG et al. [31] showed that the EGFR mutation rate in resected lung adenocarcinoma was not significantly associated with sex (females versus males: $54.5 \%$ versus $55.5 \%$ ) and smoking history in Taiwan. The present study showed that the EGFR mutation rate was 50.5\% in surgically resected specimens of lung adenocarcinoma, and the difference of EGFR mutations between sexes was also not significant. These were consistent with another report from Taiwan [31]. This implies that the Asian population is not so homogeneous with regard to the mutation rate of EGFR and as regards the influence of sex and smoking on the mutation rate.

Among the EGFR TKI-treated patients, the present study showed several different EGFR mutation types other than L858R and deletion in exon 19. The various EGFR mutations did not all have good response to EGFR TKIs. In particular, T790M was found to confer primary and acquired resistance to EGFR TKI [34]. The functional values of these different EGFR mutations are still unclear.

There was one limitation of the present study, that the EGFR copy numbers in the cancer cells of MPEs were not examined. EGFR amplification is also an important predictive factor for NSCLC patients treated with EGFR TKIs [35, 36], although studies have shown that the EGFR mutation, rather than EGFR copy numbers, was a determinant of favourable clinical outcomes in gefitinib-treated patients with NSCLC [37-39]. Another interesting issue is that further studies are necessary to elucidate whether EGFR gene amplification is also a progressive event like the EGFR mutation as shown in the present study.

There have been studies evaluating the high level of VEGF in MPE [13, 40,41], and VEGF may also have a potential role in the formation of MPE [13]. A case report has demonstrated that 
bevacizumab is active in malignant effusion [42]. However, treating malignant effusion with bevacizumab might require higher doses than simply treating the underlying cancer [42]. Therefore, an antiangiogenic therapy for the treatment of MPE may play a important role for future studies.

In the present study, $54 \%$ of patients with lung adenocarcinoma with MPEs responded to EGFR TKI treatment, and 74\% of patients with EGFR mutations responded to EGFR TKI. Furthermore, EGFR mutation analysis from pleural effusion is feasible in MPEs [8, 39, 43]. The present authors suggest performing EGFR mutation analysis in lung adenocarcinoma with MPEs to select those with the highest response rate to treatment with EGFR TKI. However, future prospective studies are needed to clarify these.

In conclusion, pleural effusion is easy to collect and epidermal growth factor receptor gene mutation analysis from malignant pleural effusions is feasible. The patients with malignant pleural effusions related to lung adenocarcinoma had a higher epidermal growth factor receptor gene mutation rate than the surgically resected specimens. Epidermal growth factor receptor tyrosine kinase inhibitor may be the treatment of choice for lung adenocarcinoma with malignant pleural effusions in east Asia.

\section{REFERENCES}

1 Jemal A, Murray T, Ward E, et al. Cancer statistics, 2005. CA Cancer J Clin 2005; 55: 10-30.

2 D'Addario G, Pintilie M, Leighl NB, Feld R, Cerny T, Shepherd FA. Platinum-based versus non-platinum-based chemotherapy in advanced non-small-cell lung cancer: a meta-analysis of the published literature. J Clin Oncol 2005; 23: 2926-2936.

3 Kris MG, Natale RB, Herbst RS, et al. Efficacy of gefitinib, an inhibitor of the epidermal growth factor receptor tyrosine kinase, in symptomatic patients with non-small cell lung cancer: a randomized trial. JAMA 2003; 290: 2149-2158.

4 Fukuoka M, Yano S, Giaccone G, et al. Multi-institutional randomized phase II trial of gefitinib for previously treated patients with advanced nonsmall-cell lung cancer (The IDEAL 1 Trial). J Clin Oncol 2003; 21: 2237-2246.

5 van Puijenbroek R, Bosquee L, Meert AP, et al. Gefitinib monotherapy in advanced nonsmall cell lung cancer: a large Western community implementation study. Eur Respir J 2007; 29: 128-133.

6 Shigematsu H, Lin L, Takahashi T, et al. Clinical and biological features associated with epidermal growth factor receptor gene mutations in lung cancers. J Natl Cancer Inst 2005; 97: 339-346.

7 Paez JG, Janne PA, Lee JC, et al. EGFR mutations in lung cancer: correlation with clinical response to gefitinib therapy. Science 2004; 304: 1497-1500.

8 Mitsudomi T, Kosaka T, Endoh H, et al. Mutations of the epidermal growth factor receptor gene predict prolonged survival after gefitinib treatment in patients with nonsmall-cell lung cancer with postoperative recurrence. J Clin Oncol 2005; 23: 2513-2520.

9 Lynch TJ, Bell DW, Sordella R, et al. Activating mutations in the epidermal growth factor receptor underlying responsiveness of non-small-cell lung cancer to gefitinib. N Engl J Med 2004; 350: 2129-2139.
10 Clinical presentation of non-small cell carcinoma of the lung. In: Pass $\mathrm{HI}$, Johnson $\mathrm{DH}$, eds. Lung Cancer: Principles and Practice. 3rd Edn. Philadelphia, Lippincott Williams \& Wilkins, 2005; pp. 291-303.

11 Light RW, Hamm H. Malignant pleural effusion: would the real cause please stand up? Eur Respir J 1997; 10: 1701-1702.

12 Brown LF, Detmar M, Claffey K, et al. Vascular permeability factor/vascular endothelial growth factor: a multifunctional angiogenic cytokine. EXS 1997; 79: 233-269.

13 Cheng D, Rodriguez RM, Perkett EA, et al. Vascular endothelial growth factor in pleural fluid. Chest 1999; 116: 760-765.

14 Hsieh WY, Chen MW, Ho HT, You TM, Lu YT. Identification of differentially expressed proteins in human malignant pleural effusions. Eur Respir J 2006; 28: 1178-1185.

15 Dai Y, Morishita Y, Mase K, et al. Application of the p53 and K-ras gene mutation patterns for cytologic diagnosis of recurrent lung carcinomas. Cancer 2000; 90: 258-263.

16 Soh J, Toyooka S, Aoe $\mathrm{K}$, et al. Usefulness of EGFR mutation screening in pleural fluid to predict the clinical outcome of gefitinib treated patients with lung cancer. Int J Cancer 2006; 119: 2353-2358.

17 Hung MS, Lin CK, Leu SW, Wu MY, Tsai YH, Yang CT. Epidermal growth factor receptor mutations in cells from non-small cell lung cancer malignant pleural effusions. Chang Gung Med J 2006; 29: 373-379.

18 Therasse P, Arbuck SG, Eisenhauer EA, et al. New guidelines to evaluate the response to treatment in solid tumours. European Organization for Research and Treatment of Cancer, National Cancer Institute of the United States, National Cancer Institute of Canada. J Natl Cancer Inst 2000; 92: 205-216.

19 American Thoracic Society, Management of malignant pleural effusions. Am J Respir Crit Care Med 2000; 162: 1987-2001.

20 Kimura H, Fujiwara Y, Sone T, et al. EGFR mutation status in tumour-derived DNA from pleural effusion fluid is a practical basis for predicting the response to gefitinib. $\mathrm{Br} \mathrm{J}$ Cancer 2006; 95: 1390-1395.

21 Kimura H, Fujiwara $\mathrm{Y}$, Sone $\mathrm{T}$, et al. High sensitivity detection of epidermal growth factor receptor mutations in the pleural effusion of non-small cell lung cancer patients. Cancer Sci 2006; 97: 642-648.

22 Vogelstein B, Fearon ER, Hamilton SR, et al. Genetic alterations during colorectal-tumour development. $N$ Engl J Med 1988; 319: 525-532.

23 Beckmann MW, Niederacher D, Schnurch HG, Gusterson BA, Bender HG. Multistep carcinogenesis of breast cancer and tumour heterogeneity. J Mol Med 1997; 75: 429-439.

24 Tang X, Shigematsu H, Bekele BN, et al. EGFR tyrosine kinase domain mutations are detected in histologically normal respiratory epithelium in lung cancer patients. Cancer Res 2005; 65: 7568-7572.

25 Tomizawa Y, Iijima H, Sunaga N, et al. Clinicopathologic significance of the mutations of the epidermal growth factor receptor gene in patients with non-small cell lung cancer. Clin Cancer Res 2005; 11: 6816-6822.

26 Matsumoto S, Takahashi K, Iwakawa R, et al. Frequent EGFR mutations in brain metastases of lung adenocarcinoma. Int J Cancer 2006; 119: 1491-1494.

27 Bae NC, Chae MH, Lee MH, et al. EGFR, ERBB2, and KRAS mutations in Korean non-small cell lung cancer patients. Cancer Genet Cytogenet 2007; 173: 107-113. 
28 Tokumo M, Toyooka S, Kiura K, et al. The relationship between epidermal growth factor receptor mutations and clinicopathologic features in non-small cell lung cancers. Clin Cancer Res 2005; 11: 1167-1173.

29 Sugio K, Uramoto H, Ono K, et al. Mutations within the tyrosine kinase domain of EGFR gene specifically occur in lung adenocarcinoma patients with a low exposure of tobacco smoking. Br J Cancer 2006; 94: 896-903.

30 Haneda H, Sasaki H, Lindeman N, et al. A correlation between EGFR gene mutation status and bronchioloalveolar carcinoma features in Japanese patients with adenocarcinoma. Jpn J Clin Oncol 2006; 36: 69-75.

31 Huang SF, Liu HP, Li LH, et al. High frequency of epidermal growth factor receptor mutations with complex patterns in non-small cell lung cancers related to gefitinib responsiveness in Taiwan. Clin Cancer Res 2004; 10: 8195-8203.

32 Sonobe M, Manabe T, Wada H, Tanaka F. Mutations in the epidermal growth factor receptor gene are linked to smoking-independent, lung adenocarcinoma. $\mathrm{Br} J$ Cancer 2005; 93: 355-363.

33 Kosaka T, Yatabe Y, Endoh H, Kuwano H, Takahashi T, Mitsudomi T. Mutations of the epidermal growth factor receptor gene in lung cancer: biological and clinical implications. Cancer Res 2004; 64: 8919-8923.

34 Shih JY, Gow CH, Yang PC. EGFR mutation conferring primary resistance to gefitinib in non-small-cell lung cancer. N Engl J Med 2005; 353: 207-208.

35 Cappuzzo F, Hirsch FR, Rossi E, et al. Epidermal growth factor receptor gene and protein and gefitinib sensitivity in nonsmall-cell lung cancer. J Natl Cancer Inst 2005; 97: 643-655.
36 Helfrich BA, Raben D, Varella-Garcia M, et al. Antitumour activity of the epidermal growth factor receptor (EGFR) tyrosine kinase inhibitor gefitinib (ZD1839, Iressa) in nonsmall cell lung cancer cell lines correlates with gene copy number and EGFR mutations but not EGFR protein levels. Clin Cancer Res 2006; 12: 7117-7125.

37 Sasaki H, Endo K, Okuda K, et al. Epidermal growth factor receptor gene amplification and gefitinib sensitivity in patients with recurrent lung cancer. J Cancer Res Clin Oncol 2007; 134: 569-577.

38 Soh J, Toyooka S, Ichihara S, et al. Impact of HER2 and EGFR gene status on gefitinib-treated patients with nonsmall-cell lung cancer. Int J Cancer 2007; 121: 1162-1167.

39 Takano T, Ohe Y, Sakamoto H, et al. Epidermal growth factor receptor gene mutations and increased copy numbers predict gefitinib sensitivity in patients with recurrent nonsmall-cell lung cancer. J Clin Oncol 2005; 23: 6829-6837.

40 Thickett DR, Armstrong L, Millar AB. Vascular endothelial growth factor (VEGF) in inflammatory and malignant pleural effusions. Thorax 1999; 54: 707-710.

41 Sack U, Hoffmann M, Zhao XJ, et al. Vascular endothelial growth factor in pleural effusions of different origin. Eur Respir J 2005; 25: 600-604.

42 Pichelmayer O, Gruenberger B, Zielinski C, Raderer M. Bevacizumab is active in malignant effusion. Ann Oncol 2006; 17: 1853.

43 Han SW, Kim TY, Hwang PG, et al. Predictive and prognostic impact of epidermal growth factor receptor mutation in nonsmall-cell lung cancer patients treated with gefitinib. J Clin Oncol 2005; 23: 2493-2501. 